\author{
Renata Vychodilová, Alena Pokorná, Hana Vrtělová ${ }^{1}$ \\ University Sports Centre Department, Faculty of Sports Studies, \\ Masaryk University, Brno, Czech Republic
}

\title{
The Fusion of Fascia-Oriented Exercise and Pilates in Rollpilates Course at Masaryk University
}

\begin{abstract}
The aim of this paper is to analyse Pilates and fasia-oriented exercise in terms of their possible interconnection. We intend to introduce the fusion of Pilates and fascia-oriented exercise in the form of a new sports course Rollpilates lectured at the Faculty of Sports studies, Masaryk University, Brno. The course was formed in the project approved as part of the Masaryk University Development Fund and involves a nouveau approach towards the interconnection of two types of exercise.

The methods include an analysis of scientific publications and educational materials dealing with Pilates and fascia-oriented exercise. In order to comprehend the theory and principles of fascia-oriented exercise and its interconnection with Pilates and to study new trends in Pilates, the work incorporates a bibliographic search, a research probe, the participation in several educational courses and the interviewing of experienced lectures of fascia-oriented and Pilates exercise, with the support of our own practical experience. Based on the analysis, a Rollpilates course was established and its programme, content and principles were defined. In order to enhance and propagate the course, educational online material was designed and displayed in the Information system of Masaryk University.
\end{abstract}

Keywords: Rollpilates course, Pilates, fascia-oriented exercise, nouveau approach

\section{Introduction}

Physical activity should be an inevitable part of life in the information society. Negative aspects of our lifestyle, such as a sedentary way of life, penetrate both our working and leisure time, and result in physical inactivity. On the contrary, there is an ever-growing variety of options for taking exercise, with new types of exercise and sports appearing nowadays. The range of exercise and sport activities at the University Sports Centre Department keeps in step with this development. The department provides university students with a wide range of sports activities. University students are offered 73 kinds of different sports and exercise programmes within the compulsory PE form and 43 kinds within the optional PE form, which

\footnotetext{
${ }^{1}$ Mgr. Renata Vychodilová e-mail: rvychodilova@email.cz, Mgr. Alena Pokorná, Ph.D., PaedDr. Hana Vrtělová
} 
altogether includes 7500 students actively doing sport and exercise on the university premises each semester. According to the survey in MUNI monthly (2015) answered by 1244 participants, 91 percent of respondents would appreciate three terms of compulsory PE instead of the two which are obligatory now. The respondents are also highly interested in more complex and new sports and exercise activities. These results correspond with our aim to open the course of Rollpilates, which combines two types of exercise. The course involves a well-established exercise of Pilates, performed on foam rollers primarily, in which a new fascia-oriented exercise is incorporated. Fascia-oriented exercise remodels the architecture of the fascial network, rehydrates and releases it, refines its proprioceptive perception and stimulates the production of its fibroblasts (Schleip 2015). It accelerates recovery after injuries, can be also employed as a prevention method against injuries and as a technique supporting the improvement in sports performance and efficiency (Myers 2009). Schleip states (2015) that a lot of observation effort has been dedicated to different training and exercise methods in sports science, but research in fascial tissue has been neglected. Fascia is elastic, and its elasticity is trainable, the architectural arrangement of the fascial network reacts to strain-loading demands. The fascial structures slowly but constantly adapt both to everyday strain and to a specific training (El-Labban et al. 1993). The interconnection of these two exercise systems follows current research findings and new trends in the world of exercise. The incorporation of fascia-oriented training into Pilates does not aim to replace, but to supplement, enrich and enhance it.

\section{Methods}

Our aim was to use an exploratory approach to comprehend current issues of fasciaoriented exercise and its incorporation into Pilates. We also made use of the experience of Pilates and fascia-oriented exercise lecturers, as well as our own experience in the field. Our competence was enhanced by participating in specific training sessions, workshops and seminars: Fascial Fitness, Rolfpilates, Myofascial Integration, Roller Mobility Workshop and Trigger Point Therapy. Having acquired the relevant knowledge and experience, the course programme and its contents were defined and the educational material was designed. The material provides a theoretical insight into the topic, introduces the theory and principles of Pilates and fascia-oriented exercise. This involves a battery of exercises, describing their setup, action, modifications, precision points and purpose, which is supported by photographic illustrations and video samples. It was created in accordance with the latest research findings in the field.

\section{Results}

The word Rollpilates consists of two parts. The word 'roll' represents a sports aid, which can be used to make exercise easier or on the contrary more difficult. This word also expresses a type of movement technique in the fascia-oriented self- 
massage. The connection of these two words indicates the interconnection between the two exercise systems involved, between the widely spread, well-established and popular exercise of Pilates and the quite nouveau fascia-oriented exercise, in which foam rollers are used.

J.H.Pilates, the founder of the Pilates method, was born in Germany. He started developing his exercise programme, called Contrology, during the WWI, when being detained as a prisoner in a camp in Great Britain. In New York, where he emigrated and opened a studio in 1926, he continued elaborating the system. His system originally focused on soldiers and war veterans. Later it was influenced by professional dancers who first appreciated his method in America, and even later it gradually became suitable for everybody regardless of age, fitness or skills. Although Pilates himself had no medical credentials and was a self-taught movement therapist, his ideas were quite original and pioneering at that time. His exercises focused on the spine work, he promoted the idea that an unhealthy spine, which in his opinion should be straightened, might be a cause of many health problems, such as asthma or low and high blood pressure (Pilates 1934). The emphasis was put on the posture, breathing and core stabilization. Although significantly influenced by many of his followers, the original system consisting of thirty-four mat exercises and six original principles are still respected. Ungarová (2012), one of the present respected authors specializing in Pilates, stresses the following set of recommendations: 'Control' as the basic principle, 'Concentration' as the awareness of the self, 'Powerhouse' as a centre where all movements should start,' Accuracy' of the whole exercise performance, 'Breathing' where the lateral type of breathing, enabling an active involvement of the diaphragm and abdominal muscles, is aimed at, and 'Smoothness or Fluency' which emphasises a smooth, continuous and logical arrangement of all the exercises and the fluent pace and rhythm. The authors of Pilates Medical (Klenková and Kazimír 2010), a medical modification of Pilates, stress the principle of Axial Stretch, which they consider the most important contribution of the method. The principle is based on the active spine extension during muscle contraction. According to the Stott Pilates manual (2001), Stott Pilates represents another latest approach and follows five basic principles: breathing, pelvic placement, rib cage placement, scapular movement and stabilization, and head and cervical placement. These principles in close cooperation create an intelligent, safe and effective exercise built on the firm foundations established by Joseph Pilates. These and other trends influence the original Pilates system, and help to absorb and incorporate the latest research findings, and enhance it.

Pilates is also rearranged under the impact of fascia-oriented exercise. The idea of the fascia-oriented Pilates appeared at the beginning of the $21^{\text {st }}$ century. The connection was inspired by Fascial Fitness, Kinesis Myofascial Integration (KMI) and the Integrated Systems Model (ISM). Fascial Fitness is a fascia-oriented exercise system with defined principles (Schleip and Muller 2013). The KMI method is a series of deep bodywork sessions working with the whole body based on the theory of longitudinal anatomy and long myofascial meridians (Myers 2009). ISM interconnects multiple sources, and its aim is to treat the whole person to achieve optimal health. The model is designed as a framework for navigating how to 
find impaired body parts, which the subsequent treatment is focused on. Once they are determined, specific training is suggested and used to improve the function of the impaired areas, and to release, control and integrate them appropriately in the movement. Pilates, Fascial Fitness and KMI are some of the sources of the ISM system (Lee 2011).

Regarding fascia-oriented exercise, Schleip et al. (2015) claim that we have long been paying attention to muscular and cardiovascular training, and to coordination practice, but the fasciae have been neglected. In human body, the connective tissue is omnipresent. It interconnects all body structures and organs, enables them to glide smoothly against each other, maintains their correct positioning within the gravitation field, and acts as an important force transmission participant in locomotion (Huijing 2007). In the course of life, the fascia system undergoes changes. Aging and other negative impacts, such as diseases, injuries, stress, overloading, painful and inflammatory processes influence its architecture, fitness and shape. The system is trainable. Although we unintentionally work with it in all exercise and training activities, new research findings bring a new, specifically targeted fascia-oriented exercise, which is more effective (Schleip et al., 2015). Fascia-oriented exercise brings the following benefits in fascia: the mechanical lengthening, hydration and release of the tissue, proprioceptive stimulation, remodelling of its architectural arrangement and the direct stimulation of fibroblasts. The system respects the following exercise principles: fascial stretching, sensory refinement, elasticity rebound and myofascial release, preparatory countermovement and the Ninja principle (Schleip and Muller 2013; Schleip et al. 2015; Myers 2009).

Concerning the fascia-oriented exercise system, different stretching types are involved as stated by Schleip and Muller (2013). Firstly, it is the slow and fast, dynamic actively-loaded stretching, where muscles are activated at their long endof-range positions and stretched fascial components are actively involved in stretching. Next, the melting stretch which corresponds to the static stretch, but the hold in positions takes about a minute or longer, which enables fascial elements to be released and stretched. The pandiculation or instinctive stretch, representing a natural free-directional stretching accompanied by yawns, which does not extend the range of motion (Lederman 2013), but in which people as well as animals naturally perceive and follow their feelings (Bertoluci 2011). Furthermore, the dynamic bouncing stretch, considered potentially harmful if performed without a proper neuromyofascial warm up, accompanied by mini-bouncing in lengthened stretch positions. In this stretching type, the active cooperation of the whole myofascial system is involved; the tendons and aponeuroses are tensioned like elastic bands and the performance of the intended movements starts with a slight pre-tensioning in the opposite direction. It increases the elastic tension in the fascia, and the energy stored in it is subsequently dynamically released (Kram and Dawson 1998). The muscles contract rather in an isometric fashion, whereas the connective tissue elements lengthen and the motion is performed with lower muscle effort (Fukunaga et al. 2002).

To adapt stretching techniques to fascia needs, diagonal, sideways, multidirectional and undulation movements, spiralling rotations should be engaged in exercise in order to target the whole network, which is present not only in the form 
of long narrow stripes, but also as membranous sheets. Since the network is omnipresent, the longest possible myofascial chains should be involved (Schleip et al. 2015; Myers 2009). Furthermore, a self-treatment massage technique with foam rollers or some other sports aids, such as foot massage balls, small balls or duoballs is involved as an important part of fascia-oriented exercise. When rolling, the body is positioned on a roller and is fluently moved forward and backward, sideways or multi-directionally over the top of roller. If performed faster, the rolling is primarily aimed at proprioceptive stimulation. If performed slowly, the rolling is primarily focused on tissue rehydration and refinement. Rubbing, pressing or moving different body parts over coarse surfaces also improve tissue proprioception. Fascia-oriented exercise should be performed smoothly, softly, gracefully, fluently and with minimum effort. Sequences are advisable to change the rhythm and frequency, to avoid jerking, abrupt movements and repetitive exercise. To improve the status of neglected fascia is a slow and long-term process and the changes in fascia tissue first come after 6-24 months of regular exercising. On the contrary, it is not very time consuming, because training twice a week for 20 minutes is sufficient (Schleip at al. 2015).

\section{Discussion}

Our goal was to design a course consisting of fascia-oriented exercise and Pilates, to find and explore their mutual aspects and to fuse these two exercise systems to reach a new, enhanced system.

As for their principles, we found out that the systems do not clash. Principles of Control, Concentration and Precision in Pilates correlate with Sensory Refinement in fascia-oriented exercise. They all indicate the necessity to be present when exercising, to be aware of what we are performing and to exercise as accurately as possible. The principles of Centring or Powerhouse, pelvic stability and balanced core muscles, and the principle of Axial Stretch, elongated muscles, associate with the concept of Fascial Stretch and Elasticity Rebound. The principle of Whole Body Movement in Pilates corresponds to Myers' concept of long myofascial meridians involvement. The principle of Flow or Smoothness and Fluency in Pilates correlates with the Ninja principle, where a smooth, graceful and fluent performance is wanted with minimum effort and noise. Although the fusion sometimes requires changes in pace, rhythm and frequency in Pilates, these are not distractive or counterproductive (Schleip et al. 2015).

As the objective of fascia-oriented exercise is to supplement other sports and exercise types, we advise to arrange specific short sequences of fascia-oriented exercise in different positions into the Pilates compositions any time during a lesson. These sequences, which take from 2-5 minutes, involve slow actively-loaded dynamic stretching, followed by fast actively-loaded dynamic stretching and rebound stretches, then by static stretching in combination with mini-bounces (the torso and arms are stretched in a static way, while the legs perform mini-bouncing or vice versa; the principle of long chain involvement is considered), completed by melting stretches for a minute. The duration of all fascia-oriented exercise 
sequences performed in one lesson altogether is designed to match the requirement to exercise about 15 minutes in a lesson. The role of the lecturer's experience and creativity plays an important role, because the exercise should often be slightly modified in accordance with the needs of the fascial network; changes in the positioning of the arms, legs, feet, or torso are desirable (Schleip and Muller 2013; Myers 2009).

Regarding particular basic mat exercises in Pilates, some of them naturally correspond to some principles of fascia-oriented exercise, since their performance fulfils the demand of stretching different myofascial lines. The stretching of the deep front meridian is involved in the Scissors, Jackknife, Shoulder Bridge, Double Leg Stretch, Hip Circles, the Hundred and the Spine Stretch Forward. The superficial front meridian is stretched in the Single or Double Leg Kick, Bicycle, Seal, Roll Up or the Single Leg Stretch. The Side Kick, Corkscrew, Mermaid Side Bends, Kneeling Side Kicks stretch the lateral line; Hip Circles, the Criss Cross, the Spine Twist and the Saw include stretching the spiral meridian; the Swan Dive, Swimming, the Roll Over and the Leg Pull Up stretch the superficial back line. Multi-directionality is involved in Hip Circles, Kneeling Side Leg and Arm Circles, preparatory countermovement in the Scissors, Spine Twist and Criss Cross, tissue rehydration in the Spine Stretch Forward, Mermaid Side Bends and the Saw (Schleip et al. 2015; Myers 2009). These aspects show that the fusion appears mutually beneficial and valuable.

Concerning foam rollers, they are used in self-treatment massage to warm up (fast performance) or refine (slow performance) proprioceptive perception, muscles and connective tissue rehydration and refinement in fascia-oriented exercise. Fast massage should be performed at the beginning, slow massage at the end of the lesson. We advise to include the foot massage at the beginning of the lesson for 1-2 minutes, as plantar fascia plays an important role in human locomotion and its release influences the whole fascial network which is connected throughout the whole body and interconnects all organs, muscles and other body structures. Rollers can also be used in Pilates sequences as a sports tool to make exercise easier when there are insufficiencies in body positioning, or as a balancing tool to make it more difficult in advanced performance.

\section{Conclusions}

The course responds to current research findings concerning Pilates and fasciaoriented exercised. The course involves Pilates exercise methods with the employment of foam rollers, and is supplemented by fascia-oriented exercise. The possibilities of their mutual complementation, overlapping and contribution were explored, their interconnection suggested and the course programme was designed.

Since we assume that the fusion of fascia-oriented exercise and Pilates enhances both concepts, we interconnected the systems into one, trying to take into consideration research findings, the exercise principles and basics, overlaps and aims they have in common, as well as differences between them, and designed a new sports course named Rollpilates. The course brings a nouveau approach; it 
combines a well-established Pilates system with a new, fascia-oriented exercise type. The course extends the range of sports courses on offer at Masaryk University to all students, including those who are not specifically talented, but are aware of the importance of active lifestyle.

Besides, we believe that our study may initiate further discussions on the topic of fascia-oriented exercise and its integration into different types of exercise and sports. Our analysis, research probe and bibliographic search showed that regarding fascia-oriented and Pilates exercise separately, lots of research studies have been done, but little research has only been done to explore the effectiveness of their fusion and its impact on human fitness, posture, health and impairment. Therefore we suggest focusing some research on this field in the future.

\section{Reference}

1. Bertolucci, L.F. (2011). Pandiculation: nature's way of maintaining the functional integrity of the myofascial system? J Bodyw Mov Ther., 15(3), 268-80.

2. El-Labban, N.G., Hopper, C., Barber, P. (1993). Ultrastructural finding of vascular degeneration in myositis ossificans circumscripta (fibrodysplasia ossificans). J Oral Pathol Med., 22 (9), 428-31.

3. Měsíčník Masarykovy university (4/2015)

4. Fukunaga, T., Kawakami, Y., Kubo, K., et al. (2002). Muscle and tendom interaction during human movements. Exercise Sport Sci R. 30 (3), 106110.

5. Huijing, P:A. (2007). Epimuscular myofascial force transmission between antagonistic and synergistic muscle can explain movement limitation in spastic paresis. J Electromyogr Kinesiol., 17 (6), 708-724.

6. Klenková, M., Kazimír, J. (2010). Bolesti v kř́ži a Pilates Medical. Nakladatelství Slovart.

7. Langevin, H.M., et all. (2010). Tissue stretch induces nuclear remodelling in connective tissue fibroblasts. Histochem Cell Biol. 133 (4), pp. 405-15.

8. Lee, D. (2011). The Pelvic Girdle. 4th ed., Churchill Livingstone Elsevier.

9. Myers, T. W. (2009). Anatomy Trains: Myofascial Meridians for Manual and Movement Therapists. Amsterdam, Elsevier Limited.

10. Pilates, J.H. (1934). Your Health. Reprinted 1998. Presentation Dynamics Inc.

11. Schleip, R., Müller, D.G. (2013) Training principles for fascial connective tissues: scientific foundation and suggested practical applications. J Bodyw Mov Ther. 17(1), 103-115.

12. Schleip, R., Avison, J., CHaitow, L., Denenmoser, S., Eddy, D. et al. (2015) Fascia in Sport and Movement. Scotland: Handspring Publishers.

13. Stott Pilates - Comprehensive Matwork Manual (2001), Matwork \& Reformer. Canada: Merrithew Corporation.

14. Ungarová, A., (2012) Pilates-praktický průvodce. Nakladatelství IKAR. 